\section{THE CHEMISTRY AND RHEOLOGY OF CLAY}

$\mathrm{T}$ HE Rheological Club and the South-Western Branch of the Chemical Society jointly held a meeting on the above subject at University College, Exeter, on May 16, and visited china clay works and the Research Laboratory of English Clays Lovering Pochin and Co., Ltd., in St. Austell, on the following day.

In an introductory talk, Dr. G. Nagelschmidt pointed out that clays are important in many branches of pure and applied science. In geology, geochemistry, pedology, agricultural chemistry and soil mechanics clays are studied with emphasis on different pro. perties according to the branch of science concerned. Clays are the raw materials in the manufacture of ceramics and refractories, bricks and cement ; certain clays are used for their adsorbing or bonding properties or as catalysts, other clays are used as fillers in a large variety of materials.

Chemistry and microscopy supplied the chief methods of studying clays in the laboratory during the nineteenth and early twentieth century, when rational and thermal analysis and measuring base exchange capacities were developed in addition to bulk chemical analysis. But these methods failed often to account for differences in more complex properties, and clay research did not develop satisfactorily until a new technique-crystal structure analysis by X-rays-had been developed and applied to other silicates.

The atomic arrangements of clay minerals follow the general rules for silicate structures developed by W. L. Bragg. They are based on hexagonal nets of silicon-oxygen tetrahedra, which are condensed with nets of similar mesh-size of aluminium, magnesium or iron hydroxide octahedra. Condensation of one of each leads to the arrangement in the kaolin group. Recent work by Brindley and others has shown that kaolinite is triclinic and strictly periodic in three dimensions, but that in halloysite there is random arrangement of the structural units $\mathrm{Al}_{2} \mathrm{Si}_{2} \mathrm{O}_{5}(\mathrm{QH})_{4}$ along $a$ and $b$; in fact, the layers are parallel and equidistant. In certain plastic sedimentary clays of the kaolin type an intermediate structure with randomness only along $b$ seems to occur. Electron micrographs were presented showing well-developed hexagonal plates with sharp corners for kaolinite, ill-defined platelets for the plastic clay and lath-or rod-shapes for halloysite.

Condensation of two tetrahedral layers with one octahedral one in between leads to the arrangement in the mica and montmorillonite groups. Isomorphous replacements occur widely in both, causing much variability in chemical composition, and, by introducing a large negative charge, producing the high base-exchange capacity of the montmorillonite group. In this group there is, as in halloysite, random arrangement of the structural units which are separated by hexagonal water layers.

Application of the new clay mineral technique has shown that most clays and soil colloids are mixtures of clay minerals, often with oxides, hydroxides and carbonates. The mineral composition often varies with grain size, and rheological data should be obtained on as well-defined monomineralic systems as possible.

Dr. M. C. MacEwan next discussed adsorption effects on clays. Halloysite and montmorillonite both are random structures similar to some organic polymers ; but they are planar rather than chain polymers, and therefore very useful for studying adsorption, which takes place in montmorillonite between two oxygen sheets and in halloysite between one oxygen and one hydroxyl sheet. The adsorption of organic molecules by montmorillonite, first believed to be due to the base-holding capacity, takes place readily with glycerol, ethylene glycol and other polar molecules, and is a type of polar adsorption. In hydrated halloysite the distance of the layers-which can be accurately measured by $\mathrm{X}$-ray diffractiondepends on the kind of organic molecule introduced. Thus the interlayer spacing decreases from $3 \cdot 65 \mathrm{~A}$. for ethanediamine to $3.05 \mathrm{~A}$. for nitromethane. This indicates increasing strength of $\mathrm{C}-\mathrm{H}-\mathrm{O}$ hydrogen bonding.

In montmorillonite, organic molecules can be arranged in thicknesses from one to three layers; thus propanol forms one, ethanol two and nitromethane and acetonitrile form three layers. The value seems in general to go parallel with the ratio of dipole moment to parachor. X-ray diffraction data may show many orders of the basal reflexion so that a one-dimensional Fourier distribution can be developed. This was shown for nitromethane. The energetic relations involved in the formation of such complexes were described, and illustrated by figures.

In the following discussion, Dr. E. W. J. Mardles spoke on some properties of kaolin dispersed in nonaqueous media, and indicated by means of $d / \tau$ (rate of shear/shearing force) diagrams how the consistency, yield value and thixctropy vary from liquid to liquid according to the dispersive power, which in turn appears to be closely associated with the degree of wetting of the kaolin by the liquid. In mixed liquids the properties of the clay systems vary in an interesting manner with change of com. position ; thus, the thixotropy and rate of flocculation of bentonite clay in water can be enhanced by the addition of 20 per cent by volume of alcohol, although the ethyl alcohol alone is a good dispersive agent. With the addition to a clay dispersion of a small amount of a soluble colloidal substance, such as, for example, a resin or cellulose derivative, the character of the clay dispersion changes in great measure to that of the colloid itself; evidence for this was provided in the form of diagrams and models showing the sediment volumes of kaolin in binary and ternary mixtures of liquids, with and without the colloidal additions. He also mentioned a recent paper by N. J. Denissov and P. A. Rehbinder (C.R. Doklady. U.R.S.S., 54, 519; 1946) on the colloid-chemical nature of cohesion in argillaceous rocks, where the authors trace observed differences in rigidity and consolidation of naturally occurring clays to adsorbed layers of colloidal silicates on the clay particles.

H. H. Macey next gave a paper on the rheological properties of clay, in which he limited his remarks to the plastic state. Two apparently incompatible theories of the structure of plastic clay have been advanced at various times in order to explain their rheological properties. One developed from the earlier theories of a rigid water film surrounding the clay particle, replacing it by a potential field between opposing clay surfaces, whereby those surfaces appear to repel one another. The second is that of a honey. comb structure, in which the clay particles are in contact at certain points. It is natural that the former should arise in the field of ceramics, where the clay is a dynamic material, and the latter in 
agriculture, where it is more static. Neither theory is entirely satisfactory; arguments can be advanced against both. On the whole, in Mr. Macey's opinion, the former is to be preferred. It gives the more logical interpretation of rheological properties. Shear hardening, for example, is due to rearrangement of the particles into systems of smaller potential energy. Plastic clay is outstanding in that the greater the rate of shear, the greater the deformation before failure; and this can be explained by the hysteresis which is known to exist in the change of moisture-content with applied pressure between porous pistons. Differences in plastic properties become associated with differences in particle size, distribution and packing.

Pictures were shown of drying cracks in extruded bricks and other ceramic materials, and illustrations given of the very great increase in plasticity or deformation before rupture which can be obtained in some clays by removing occluded air.

In the following discussion Dr. G. Scott-Blair referred to earlier work on the effect of de-airing wet clay slips. Dr. L. N. O. Clark suggested that it might be possible to throw some light on the question of honeycomb structure by following a procedure worked out for the preparation of light magnesium oxide. In this a gel in water is taken at high pressure above the critical temperature, the water removed as gas and the solid but tenuous structure cooled. The liquid water is thus removed without a phase change, and the most delicate structure can be preserved.

If the structure were held by electrical forces one would expect a relationship between its strength with the dielectric constant of the medium.

Dr. Emödi gave arguments in favour of the honeycomb theory; but some of these arguments applied, as Dr. Treloar pointed out, to more dilute systems than to the plastic state.

G. N.

\section{SELECTION FOR MANAGEMENT}

$\mathrm{T}$ HE discussion on selection for management arranged by Section J (Psychology) of the British Association on August 29 fully conformed to the general theme of the Dundee meeting suggested by the Council of the Association. Essentially this discussion considered the methods of officer selection developed by the Services during the War, and the way in which the principles of such methods and the experience gained in using them, rather than the exact methods themselves, could be applied to the problem of selection for management. The magnitude of this problem has been emphasized in the recent Urwick Report on Education for Management. On the assumptions of that Report, some twelve thousand recruits are required annually to maintain the supply of half a million or so managers ; this obviously demands all the help which the comparatively small number of psychologists can afford.

Dr. T. Ferguson Rodger's admirable paper gave a very clear account of the development of methods of officer selection with which he was associated in the Army, and two of the six reasons he gave for the introduction of new techniques of selection in 1941 may have some bearing on the selection of managers. In industry as in O.T.C. units, morale may be affected by a high rate of rejection of candidates; while, just as in the Army the wide- spread dissatisfaction with the system of short inter. views by a small board of senior officers made it important to seek a method that would ensure that justice was manifestly done, so in industry it is no less important from the point of view of production and incentives that the selection of men for management should be quite free from favouritism or nepotism. Dr. Rodger emphasized here the necessity of paying attention to the attitudes and prejudices which are expressive of the cultural traditions of the institution or industry, and for this very reason the methods most effective for a particular Service such as the Army cannot be rigidly applied to another institution or another Service.

With this warning Dr. Rodger described the methods ultimately adopted, bringing out clearly the way in which the technical officers, such as psychologists and psychiatrists, who were members of the selection boards, were used to produce the information in such a form that it could be weighed by others. Dr. Rodger directed particular attention to the importance of group discussion and of the principle of the leaderless group in which a candidate might prove his ability to lead by actually taking command of a situation by common consent.

If Dr. Rodger indicated some of the limitations of the exact methods of selection used in the Army, Mr. A. Rodger brought out some further points which need to be considered in applying such experience in the field of industry or business. Emphasizing the fact that improvement of occupational selection does not necessarily involve the use of elaborate modern techniques of assessment, he pointed out that the chief requirement is a reasonably clear notion of what we are trying to assess. The first question to be answered is, "What are we looking for in these candidates ?" This would not be answered merely by composing lists of 'qualities' desired. It is usually more profitable to compile lists of 'situations' which have to be handled in the occupation under review, and to consider each candidate's probable effectiveness in them in the light of relevant evidence collected from every available source.

The process of selection, moreover, said Mr. Rodger, should not be divorced from that of recruitment; failure to throw up suitable candidates for promotion might well be due to failure to secure initially recruits of the proper quality. Again, if the psychologist is to assist in the selection of men for management, he must have more than superficial knowledge of the nature of the duties the candidate would be expected to perform. Ho must be fully informed not only about the general nature of such duties but more specifically of what may be termed the danger spots, or those situations in which trouble or difficulty in a particular occupation is specially liable to arise. A good selector is not himself necessarily a good manager or administrator, but knowledge of such problems or situations is far more important than lists of necessary qualities in judging the probable effectiveness of a candidate. Mr. Rodger also referred to the value of group discussions among candidates themselves and, in urging that the interview should be troated seriously, observed that the important questions are not thosewhich the selection board asks the candidate, but those that the members of the board would afterwards ask thernselves about the candidate.

These two papers put the whole discussion on a firm practical basis, and in themselves showed how large a contribution psychology could make in this 